ISSN: 0213-3563

https://doi.org/10.14201/azafea20212383106

\title{
UN DELITO EN BUSCA DE JUSTIFICACIÓN: \\ LA HUMILLACIÓN O DESCRÉDITO DE COLECTIVOS DISCRIMINADOS ${ }^{1}$
}

\author{
A Crime Looking for Justification: \\ Humiliation or Dicredit of Discriminated Groups
}

Patricia Laurenzo CoPello

Universidad de Málaga

Recibido: 25 de junio de 2021

Aceptado: 19 de octubre de 2021

\section{RESUMEN}

El presente trabajo está destinado a estudiar el contenido y alcance del delito de humillación, menosprecio o descrédito de colectivos discriminados que introdujo la reforma penal de 2015 en el artículo 510.2 a) del Código penal y que se ha identificado de forma unánime como un delito de odio. Se parte de un análisis crítico de la aplicación que están haciendo del mismo los tribunales de justicia para luego centrarse en el significado de la categoría conceptual de delitos de odio. A partir de ahí se propone una interpretación restrictiva basada en los fines del derecho penal antidiscriminatorio.

Palabras clave: Delitos de odio; injurias colectivas; discriminación; dignidad; minorías.

\section{ABSTRACT}

The porpouse of this paper is to study the content and scope of the offence of humiliation, dispragement or dicredit of discriminated groups that introduced the 2015 criminal reform in article 510.2 a) of the Penal Code and

1. Este trabajo se realiza en el contexto del Proyecto de Investigación "Comportamientos basados en el discurso del odio” (DER 2017-84178-P) financiado por el Ministerio de Ciencia e Innovación del Gobierno de España. 
that has been identified as a hate crime. The study contains a critical analysis of the jurisprudence and then focuses on the meaning of hate crimes in order to propose a restrictive version of this offence based on the purposes of the anti-discrimination criminal law.

Key words: Hate crimes; collective insults; discrimination; dignity; minorities.

\section{INTRODUCCIÓN}

La reforma del Código penal introducida por la Ley Orgánica 1/2015 supuso un avance punitivista muy significativo en el derecho penal antidiscriminatorio que se justificó con el argumento de la necesidad de adecuar nuestra legislación a la normativa europea en la materia. Como bien ha demostrado la doctrina más reciente, ese argumento en realidad ha sido más una excusa que una causa justificada ya que muchos de los cambios introducidos (sobre todo en el art. $510 \mathrm{CP}$ ) no venían impuestos por Europa. Entre ellos se encuentra el delito recogido en el renovado art. 510.2 a) del Código penal que, emulando la redacción del delito de humillación a las víctimas del terrorismo, sanciona los actos que lesionen la dignidad de las personas mediante acciones que entrañen humillación, menosprecio o descrédito de algún grupo vulnerable protegido por la ley, una parte del mismo o alguno de sus miembros. Quizás por inercia interpretativa, muchos siguen refiriéndose a este delito como un caso de "injurias colectivas", en recuerdo del primigenio art. 510.2. Pero basta un prolijo repaso de los casos en que los tribunales están aplicando el delito en la práctica para comprobar que en realidad el precepto abre las puertas para ampliar el ámbito de punición mucho más allá de las concretas manifestaciones de descrédito dirigidas a un grupo social discriminado.

Es conveniente, por tanto, prestar atención a la jurisprudencia de los últimos años para verificar qué efectos reales está teniendo la tipificación autónoma de las conductas de discriminación que se concretan en actos vejatorios. Este análisis permitirá descubrir que la interpretación del precepto viene muy condicionada por una categoría importada del derecho anglosajón que en los últimos tiempos ha adquirido gran protagonismo entre nosotros: los delitos de odio. El problema es que, como veremos, la recepción de los hate crimes en el ámbito jurídico español está plagada de inconsecuencias y falta 
de claridad que muchas veces influye de manera negativa en la aplicación de la ley penal.

El presente estudio parte de la convicción de que la categoría de delitos de odio ha de identificarse de forma plena con el derecho penal antidiscriminatorio, lo que implica situar el objeto de tutela en la protección de los colectivos que por alguna circunstancia identitaria se apartan del modelo de normatividad social imperante, encontrándose en una posición de partida desfavorable que requiere especial atención para asegurar el pleno ejercicio de los derechos fundamentales de todos sus miembros.

Este punto de partida nos servirá para fundamentar una interpretación restrictiva del delito recogido en el artículo 510.2 a) del Código penal. A ello dedicaremos las páginas que siguen.

\section{GÉNESIS LEgISLATIVA: LOS PRECEDENTES DEL ACTUAL DELITO DE HUMILLACIÓN DE COLECTIVOS DISCRIMINADOS}

Los primeros pasos legislativos en el derecho penal español dirigidos a sancionar las conductas racistas y xenófobas surgieron en los años noventa dentro de un contexto político y social marcado por la inesperada reaparición de prácticas genocidas en pleno territorio europeo con motivo del conflicto bélico de los Balcanes y el paralelo ascenso de movimientos negacionistas de ideología neonazi que favorecieron episodios de carácter violento en distintos puntos del continente. Esas son las razones que se mencionan en la Exposición de Motivos de la Ley Orgánica 4/1995 para incorporar a la legislación penal las primeras figuras de apología del genocidio, provocación a la discriminación y la agravante de actuar por motivos racistas:

La proliferación en distintos países de Europa de episodios de violencia racista y antisemita que se perpetran bajo las banderas y símbolos de ideología nazi obliga a los Estados democráticos a emprender una acción decidida para luchar contra ella. Ello resulta tanto más urgente cuando se presencia la reaparición en la guerra que asola la antigua Yugoslavia de prácticas genocidas que 1os pueblos europeos creían desterradas para siempre.

A ello hay que añadir el especial impacto que tuvo entre nosotros el movimiento negacionista debido a las iniciativas procesales que tomaron algunas personas de origen judío con motivo de la difusión pública de opiniones y libelos que ponían en duda el holocausto nazi utilizando juicios despectivos 
e hirientes hacia sus víctimas. Sin duda el caso más importante por su influencia directa en las reformas penales de 1995 (tanto la ya mencionada LO 4/1995 como el nuevo Código penal que se aprobó ese mismo año) fue el que dio lugar a la Sentencia del Tribunal Constitucional 214/1991, de 11 de noviembre, calificada por Cuerda Arnau como "una declaración institucional de contenido ético en contra del racismo y la discriminación” que "sentó las bases de la reforma penal que nos ocupa" (1995, p. 101). Una mujer de origen judío llamada Violeta Friedman demandó por protección civil del honor al antiguo miembro de las Waffen SS León Degrelle, que había llamado públicamente mentirosos a los judíos sometidos a las torturas de los campos de concentración nazis -entre los que ella se encontraba- utilizando palabras profundamente despectivas hacia todo el colectivo. El alto Tribunal entendió que los juicios ofensivos hacia el pueblo judío expresados por el Sr. Degrelle contenían afirmaciones con connotaciones racistas y antisemitas que no podían quedar amparadas por los derechos a las libertades ideológica y de expresión al tratarse de "imputaciones efectuadas en descrédito y menosprecio de las propias víctimas" (el pueblo judío) que atentaban contra el derecho al honor de las personas afectadas y contra la dignidad humana, ya que "la dignidad como rango o categoría de la persona como tal, del que deriva, y en el que se proyecta el derecho al honor (art. 18.1 C.E.) no admite discriminación alguna por razón de nacimiento, raza o sexo, opiniones o creencias. El odio y el desprecio a todo un pueblo o a una etnia (a cualquier pueblo o a cualquier etnia) son incompatibles con el respeto a la dignidad humana" (F.J. 8).

Este pronunciamiento jugó un papel importante en la decisión políticocriminal de tipificar no solo la negación o trivialización del genocidio que tantos altibajos ha sufrido en su todavía corta historia, sino también las conductas "destinadas a generar menosprecio o sentimientos de hostilidad contra determinados grupos étnicos, de extranjeros o inmigrantes, religiosos o sociales”, como concluía la mencionada Sentencia 214/1991. Y para que no se le escapara la tutela del bien jurídico honor que había jugado un papel tan decisivo en la declaración constitucional contra el racismo y la xenofobia, el legislador del 95, además de castigar las conductas de provocación a la discriminación, al odio o a la violencia por motivos racistas, antisemitas u otra clase de discriminación (recogidas en el primigenio art. 510.1), añadió una figura específica de injurias colectivas en los siguientes términos:

Serán castigados con las mismas penas [prisión de uno a tres años y multa de seis a doce meses] los que, con conocimiento de su falsedad o temerario 
O DESCRÉDITO DE COLECTIVOS DISCRIMINADOS

desprecio hacia la verdad, difundieren informaciones injuriosas sobre grupos o asociaciones en relación a su ideología, religión o creencias, la pertenencia de sus miembros a una etnia o raza, su origen nacional, su sexo, orientación sexual, enfermedad o minusvalía (art. 510.2 C.P. en su versión original vigente hasta 2015).

No faltaron voces críticas que alegaron la falta de necesidad de esta nueva figura ante la posibilidad que había abierto el propio Tribunal Constitucional de considerar como sujeto pasivo del delito (común) de injurias a grupos o colectivos de personas como los que se pretendía proteger con el nuevo art. 510.2 y no solo a individuos concretos (Muñoz Conde, 2010, p. 841). Pero incluso sin juzgar esta opinión algo discutible, lo cierto es que en su versión original de 1995, el delito de injurias colectivas de carácter discriminatorio no dejaba de ser una figura bastante contenida en extensión, ya que únicamente recogía un supuesto de difusión inveraz de informaciones de contenido injurioso (que además debían afectar al colectivo como tal y no solo a alguno de sus miembros), dejando al margen las meras opiniones o expresiones despectivas o humillantes. Un criterio restrictivo que lamentablemente ha desaparecido en la reforma introducida por la LO 1/2015, de 30 de marzo, que extiende de forma muy significativa el ámbito de comportamientos prohibidos y además amplía los posibles sujetos pasivos del delito, haciéndolo extensivo (al menos en su versión literal) a los miembros individuales de alguno de los colectivos protegidos. Dice el reformado art. 510.2:

Serán castigados con la pena de seis meses a dos años de prisión y multa de seis a doce meses:

a) Quienes lesionen la dignidad de las personas mediante acciones que entrañen humillación, menosprecio o descrédito de alguno de los grupos a que se refiere el apartado anterior, o de una parte de los mismos, o de cualquier persona determinada por razón de su pertenencia a ellos por motivos racistas, antisemitas u otros referentes a la ideología, religión o creencias, situación familiar, la pertenencia de sus miembros a una etnia, raza o nación, su origen nacional, su sexo, orientación o identidad sexual, por razones de género, enfermedad o discapacidad...

El Preámbulo de la LO 1/2015 justifica esta reforma en la necesidad de trasponer al derecho español la Decisión Marco 2008/913/JAI del Consejo de la Unión Europea relativa a la lucha contra determinadas formas y manifestaciones de racismo y xenofobia mediante el Derecho penal. Pero como bien dice Portilla Contreras (2016, p. 406), ninguna de las conductas definidas 
en el apartado segundo del art. 510 aparecen en el listado de delitos de carácter racista y xenófobo que describe la norma comunitaria (limitados a la incitación pública a la violencia o al odio por motivos discriminatorios y a diferentes formas de apología del genocidio y de otros delitos de carácter internacional, además de la circunstancia agravante de actuar por motivos racistas o xenófobos que ya existía en nuestro ordenamiento).

Si atendemos a la voluntad del legislador, parece que se trata de un intento deliberado de ampliar el ámbito de punición de los llamados "delitos de odio" a todos los actos de humillación, menosprecio o descrédito contra los grupos protegidos o contra alguno de sus integrantes, emulando de algún modo al delito de humillación de las víctimas del terrorismo (art. $578 \mathrm{CP}$ ), también recogido por la jurisprudencia y buena parte de la doctrina dentro de la difusa categoría de comportamientos de odio.

Cancio Meliá y Díaz López entienden que el delito de humillación a las víctimas del terrorismo (art. $578 \mathrm{CP}$ ) constituye una forma de discurso de odio porque se dirige contra un colectivo vulnerable, pero precisamente por eso consideran que sería más adecuado castigar estos casos a través del art. 510 y no como un delito de terrorismo (2019, p. 247). El Tribunal Supremo, por su parte, afirma de modo contundente que el 578 "penaliza la humillación que está inserta en el discurso del odio" (SSTS 623/2016, de 13 de junio y 4/2017, de 18 de enero).

Lo cierto es que tanto el abandono de la estructura típica propia del delito de injuria como la previsión legal de un posible sujeto pasivo individual han venido a perturbar de forma muy significativa la interpretación del renovado art. 510.2 del Código penal. Y mucho más si nos dejamos guiar por el ya mencionado Preámbulo de la LO 1/2015 que apunta a la aplicación de este delito incluso en los casos en que la conducta de humillación o desprecio carezca de aptitud para favorecer un clima social de violencia u hostilidad hacia el colectivo protegido, como se infiere del pasaje en el que afirma que se tipifican "los actos de humillación o menosprecio contra ellos [los grupos protegidos] y el enaltecimiento o justificación de los delitos cometidos contra los mismos o sus integrantes con una motivación discriminatoria, sin perjuicio de su castigo más grave cuando se trate de acciones de incitación al odio o a la hostilidad contra los mismos, o de conductas idóneas para favorecer un clima de violencia" (cursiva añadida).

Poco queda en este delito de aquella tímida figura de injurias colectivas que se incorporó al Código penal en el año 1995 para contener la difusión de 
informaciones falsas de carácter infamante contra ciertos colectivos señalados por sus características identitarias. Lo que ahora recoge el art. 510.2 a) es algo mucho más amplio e indeterminado, a medio camino entre los delitos contra el honor y los delitos contra la integridad moral, aunque sin el factor de contención de la gravedad del ataque al bien jurídico que exigen estas figuras delictivas. Una nueva manifestación de la política legislativa apresurada y poco reflexiva característica de nuestro tiempo, siempre arrastrada por los vaivenes de la opinión pública y los grupos de presión influyentes que no pocas veces conduce a una exacerbación de la intervención penal difícilmente justificable (Díez Ripollés, 2013, p. 175). Un breve seguimiento de la aplicación jurisprudencial del artículo 510.2 servirá para ilustrar de manera práctica las consecuencias de esta forma desordenada de legislar.

\section{3. ¿QUÉ CASTIGAN LOS TRIBUNALES?}

Veamos algunos ejemplos de condenas recientes por el delito del art. $510.2 \mathrm{a}$ ):

Un grupo de varones jóvenes, entre los que había tres menores de edad, se encontraron una madrugada en la calle con un hombre vestido de mujer y le increparon por su condición sexual con expresiones como "la vamos a liar bien gorda con los maricones de mierda", tras lo cual uno de ellos le propinó un puñetazo ocasionándole lesiones leves. La Audiencia Provincial de Madrid confirmó la condena del Juez de Menores consistente en ocho meses de internamiento en centro semiabierto (SAP Madrid, Sección 4a , 107/2019, de 25 de marzo).

Un grupo de cuatro varones que caminaban por una calle de Madrid se cruzaron con un muchacho y varias chicas y, acercándose a ellos, comenzaron a imitar la forma de hablar del muchacho, tras lo cual uno de los agresores le propinó un golpe en la cara y otro un puñetazo. Cuando las amigas de la víctima les preguntaron por qué le pegaban, uno de ellos contestó "porque es un maricón de mierda y se lo merece". Los autores fueron condenados a ocho meses de prisión y siete de multa por el delito del art. 510.2 a), además de una pena de multa por lesiones leves (SAP Madrid, Sección 15, 676/2017, de 30 de octubre).

Mientras paseaba por una calle de Madrid, un hombre se encontró con una mujer de nacionalidad brasileña y, sin mediar altercado alguno, se dirigió a ella diciéndole "solo venís a traer violencia, a quedarse preñadas, se te ve en la cara que no tienes documentación", ideas que ratificó cuando llegó la policía con expresiones tales como: "Yo amo a mi país y no a la mierda de extranjeros que está viniendo, dominicanos, moros, panchos, fui militar y estuve en la marcha 
vede, los extranjeros solo vienen a traer violencia, no contribuyen con nada, solo quieren tener hijos en nuestro país”. Por sentencia de conformidad fue condenado a seis meses de prisión y seis meses de multa (SAP Madrid, Sección $17^{\text {a }}$, 95/2021, de 22 de febrero).

Un hombre se cruzó con una mujer dominicana y su hija y, sin motivo alguno, le espetó: “iros a vuestro puto país, negratas, venís a quitarnos nuestros trabajos”, tras lo cual agredió a la mujer con varios golpes. Fue condenado a seis meses de prisión y multa por un delito del art. 510.2a), además de la pena por el maltrato de obra (SAP Santander, Sección 1a, 288/2020, de 2 de diciembre).

Un hombre le dio un golpe al móvil de un ciudadano ecuatoriano que estaba mandando un wasap al tiempo que le decía: "vete a tu puto país”, "que se vayan a su puto país los putos panchitos que solo vienen a joder”. Fue condenado a tres meses de prisión, pena atenuada por la ingesta de alcohol (SAP Barcelona, Sección 10a , 609/2020, de 23 de noviembre).

Un grupo de varones agredió con varios golpes a una pareja gay que estaba cogida de la mano a las puertas de un pub tras insultarles uno de ellos con términos tales como "maricones de mierda, gays de mierda, te voy a matar maricón de mierda”. Se dictó sentencia de conformidad por la que fueron condenados a seis meses de prisión y multa por el delito del art. 510.2.a), además de las penas correspondientes a las lesiones leves. (SAP Valencia, Sección $5^{\text {a }}$, 254/2020, de 14 de julio).

Sin ninguna intención de minimizar el problema que suponen las ideas racistas, xenófobas u homófobas (entre otras formas de discriminación) en un Estado democrático que debe garantizar el derecho de toda la ciudadanía a expresar libremente su forma de ser y de sentir sin temor a ser agredidos simplemente por sus características identitarias, los ejemplos anteriores ponen de manifiesto hasta qué punto resulta peligroso acudir al derecho penal como prima ratio para contener las consecuencias de ese tipo de comportamientos. El recurso a la pena privativa de libertad para sancionar manifestaciones aisladas de desprecio al diferente, sin exigir ningún otro componente que conceda gravedad a la conducta agresora, implica un salto cualitativo en la intervención penal que choca de manera frontal con el principio de proporcionalidad y encuentra difícil justificación en el contexto de un ordenamiento punitivo que ya contaba desde hace tiempo con una agravante genérica de discriminación (art. 22.4 $\mathrm{CP}$ ) capaz de recoger ese añadido de gravedad que comportan las agresiones violentas dirigidas contra personas que por alguna seña de identidad se apartan del modelo social preponderante, constriñendo así sus expectativas de ejercicio pleno de los derechos fundamentales. 
O DESCRÉDITO DE COLECTIVOS DISCRIMINADOS

La mayoría de los casos relatados arriba son supuestos de lesiones leves o malos tratos de obra (art. $147 \mathrm{CP}$ ) donde el componente discriminatorio se podía haber recogido sin problema alguno aplicando la agravante de discriminación del art. 22.4 ${ }^{a}$ del Código penal, lo que hubiera dado lugar a una pena mucho más ajustada a la entidad real de los hechos enjuiciados (en general de poca importancia por su carácter aislado).

De hecho, así lo ha entendido un sector de la jurisprudencia que, a diferencia de los ejemplos antes expuestos, se viene negando a aplicar el delito del art. 510.2 cuando la conducta racista carezca de aptitud para trascender de algún modo al colectivo en su conjunto. En este sentido dice con buen criterio la Sentencia de la Audiencia Provincial de Barcelona, Sección 6a , 736/2019: lo cierto es que la virtualidad ofensiva de la conducta ha de proyectarse no sólo sobre la persona a la que afecta sino sobre todo el grupo, aun cuando lo sea de modo meramente potencial. La conducta ha de revestir especial gravedad y ha de ir tendencialmente dirigida a demonizar al colectivo frente a la opinión pública, construyendo la imagen del grupo y de sus miembros como seres inferiores carentes de dignidad.

Como se ve, hay dos líneas de interpretación muy diferentes en el ámbito judicial. Una, de carácter claramente restrictivo, intenta contextualizar el alcance y contenido del art. 510.2 a) a partir de la naturaleza de los llamados "delitos de odio", lo que conduce a dar prioridad a una interpretación teleológica que sitúa la finalidad de este tipo penal en la tutela de ciertos colectivos vulnerables en razón de la etnia, nacionalidad, orientación sexual o cualquier otra de las características de identidad que menciona el precepto, de modo tal que solo se consideran cumplidos los requisitos típicos cuando el comportamiento racista (en sentido amplio) reviste la suficiente gravedad para interpretarlo como una humillación hacia el grupo en su conjunto, aunque la ofensa vaya dirigida a una o varias personas concretas (así SAP León, Sección $3^{\mathrm{a}}, 376 / 2020$, de 12 de noviembre).

Un ejemplo de estas características es el episodio que protagonizaron algunos hinchas del equipo de fútbol PSV Eindhoven en la Plaza Mayor de Madrid arrojándole monedas al suelo a cuatro mujeres rumanas que se habían acercado a pedir limosna, obligándolas a agacharse, a correr y hasta a hacer flexiones, llegando uno de ellos a exhibir un billete de cinco euros que procedió a quemar cuando las mujeres corrieron a buscarlo, todo ello en medio de burlas y comentarios vejatorios. Este caso se resolvió con una sentencia de conformidad en la que paradójicamente solo se aplicó una pena de tres meses 
de prisión (suspendida) y tres meses de multa (SAP Madrid, 344/2020, de 17 de septiembre).

En ocasiones, la interpretación restrictiva del art. 510.2 a) la extraen los tribunales de su plena identificación con los delitos contra el honor, hasta el punto de definir la conducta típica como "una modalidad del delito de injurias, agravada por la condición del sujeto pasivo” (SAP Barcelona, Sección $5^{a}$, 570/2019, de 16 de septiembre). Este punto de vista permite llegar por otra vía a la misma exigencia de gravedad de la lesión del bien jurídico que veíamos arriba, ya que el tipo común de injurias expresamente exige que la ofensa sea tenida en el concepto público por grave (art. $208 \mathrm{CP}$ ), conformando así una de las exigencias mínimas para que la lesión del honor resulte relevante para el derecho penal. Cosa distinta es que esta interpretación sea acorde con la actual redacción del precepto que comentamos, puesto que, como ya vimos al analizar su evolución legislativa, desde la reforma de 2015 es muy difícil seguir calificándolo como un simple caso de injurias agravadas. Sobre ello volveremos luego.

La identificación de la conducta del 510.2 con el delito de injurias sirve a este sector de la jurisprudencia para calificar muchos de los casos que son sometidos a su juicio como simples "vejaciones injustas" hoy despenalizadas (véanse, por ejemplo, SSAP Barcelona, Sección $2^{\mathrm{a}}$, 54/2019, de 18 de julio y 543/2019, de 11 de julio, entre otras).

Frente a estos esfuerzos de interpretar de forma restrictiva el tipo penal que nos ocupa, existe una segunda línea en la jurisprudencia que se muestra más apegada a la interpretación gramatical y de ahí extrae un alcance mucho más amplio del delito. Así, partiendo de que el art. 510.2 a) es un "delito de resultado", se considera aplicable siempre que se produzca un acto de humillación o descrédito hacia una persona por razón de alguna de las causas previstas en la ley, sin importar su mayor o menor gravedad ni las circunstancias concretas del hecho. La referencia al delito de resultado en realidad debe entenderse en el sentido de que se trata de un delito de lesión, porque el tipo exige expresamente la lesión de la dignidad, en contraposición al 510.1 que es un delito de peligro abstracto.

Este es el criterio de la Circular de la Fiscalía General del Estado 7/2019, que establece como bienes jurídicos tutelados tanto el honor como la dignidad. 
Lo curioso de este punto de vista es que en lugar de conceder a la exigencia de lesión del bien jurídico un papel limitador del alcance del tipo penal, en este caso se utiliza al revés. En efecto, en contra de la pacífica opinión que atribuye a los delitos de peligro abstracto un efecto expansivo de la intervención penal frente a los delitos de lesión, aquí se razona exactamente al contrario y se concluye que como el delito exige la lesión de la dignidad, no hay ninguna posibilidad de restringir su alcance en función de otros posibles elementos configuradores del merecimiento de sanción penal, como podría ser la entidad del ataque al bien jurídico o el fin perseguido por la norma. Aferrándose a una interpretación gramatical poco contextualizada, este sector de la jurisprudencia entiende que el art. 510.2 comprende cualquier acto objetivamente humillante o vejatorio para la víctima (aunque no sea público ni tenga gravedad alguna) que esté determinado por una motivación racista o discriminatoria del autor, entendiendo por tal, la animadversión que siente el autor hacia la persona (o el colectivo) por razón de alguna de las causas definidas en la ley (así, entre muchas otras, SAP Madrid, Sección 15, 676/2017, de 30 de octubre).

Las consecuencias insatisfactorias a las que lleva esta interpretación extensiva se perciben con claridad en un caso resuelto por la Audiencia Provincial de Madrid en que una pareja gay fue invitada por un guarda de seguridad a abandonar un centro comercial debido a que iban de la mano y se besaron en alguna ocasión, provocando incomodidad a otros clientes, en opinión del vigilante. Aunque la Audiencia consideró cumplidos todos los requisitos típicos y confirmó la condena por el art. 510.2 a), se vio obligada a moderar la pena con el siguiente razonamiento: si bien es cierto que la conducta del vigilante se incardina en el tipo penal descrito por resultar despreciativa hacia los perjudicados por su orientación sexual, lo que constituye una innegable lesión de la dignidad de las personas que se configura como un derecho básico para garantizar la convivencia y la paz social en un Estado Democrático de Derecho, no lo es menos que la misma no es merecedora de un especial reproche penal. Téngase en cuenta a tales efectos que la conducta no parece sino aislada; que en ningún caso vino acompañada de ninguna otra conducta gravosa para algún bien jurídico de la pareja (palabras o gestos insultantes); que la misma no tuvo más alcance que el estrictamente concernido a los dos perjudicados; y que, en definitiva, gracias también a la responsable actitud de las víctimas, fue, pese a todo, sutil en las formas sin que alcanzara publicidad alguna ni en ese momento, ni con posterioridad, de manera que resultara más dañada la dignidad personal de los perjudicados y del colectivo protegido al que pertenecen (SAP Madrid, Sección 1ª ,551/2020, de 17 de noviembre). 
Un problema importante de esta última versión (además de conducir a resultados punitivos que los propios jueces consideran injustos) es que queda sin explicación el porqué de un nuevo delito contra la dignidad en un Código penal que desde hace años recoge esta clase de conductas a través de la figura genérica del art. 173.1 (delito contra la integridad moral) y con una pena nada desdeñable.

La Circular 7/2019 de la Fiscalía General del Estado acepta esta duplicidad legislativa y propone un concurso de normas por especialidad en favor del 510.2 a).

Una interpretación sistemática llevaría a plantearse qué sentido tiene que el legislador haya duplicado una misma conducta típica en dos preceptos distintos y en títulos protectores de bienes diferentes (al menos parcialmente diferentes). Una respuesta podría ser que el art. 510.2 tiene la finalidad específica de sancionar los atentados a la dignidad por motivos racistas, xenófobos u otros semejantes, afectando así el derecho a no ser discriminado de la víctima. Sin embargo, una vez más habría que recordar que ese añadido de ilicitud se puede cubrir generalmente con la agravante genérica de discriminación del art. $22.4^{\circ}$, haciendo innecesario un delito autónomo. La única explicación que queda disponible es el dudoso argumento esgrimido en algunos pronunciamientos judiciales en el sentido de que el art. 510.2 no requiere gravedad alguna en el ataque a la dignidad (requisito que sí contiene el delito genérico contra la integridad moral). Pero como bien sostiene el sector de la jurisprudencia que ha optado por una interpretación restrictiva, esta conclusión es difícilmente justificable en el contexto de los llamados delitos de odio, cuyo fin es proteger a grupos o colectivos sociales marcados negativamente por alguna seña de identidad, lo que se traduce en la necesidad de que el ataque a la dignidad de las personas concretamente afectadas trascienda de algún modo a la seguridad del grupo (Landa Gorostiza, 2018, pp. 82 y s.).

\section{ATENTADOS A LA DIGNIDAD POR MOTIVOS DISCRIMINATORIOS Y DELITOS DE ODIO}

Cualquiera sea la línea interpretativa por la que opte cada tribunal, es unánime la tendencia a calificar los actos de humillación, menosprecio o descrédito por motivos discriminatorios recogidos en el art. 510.2 CP como un supuesto de "delitos de odio". Esta conclusión se extrae básicamente de dos factores: por un lado, de la ubicación sistemática de estos atentados a la dig- 
nidad en el mismo precepto que castiga la incitación pública al odio, la discriminación o la violencia por motivos racistas u otra clase de discriminación y, por otro, debido a su semejanza con el delito de humillación de las víctimas del terrorismo que tanto el Tribunal Supremo como el Constitucional vienen calificando desde hace tiempo como una manifestación del discurso del odio (véanse, por ejemplo, STC 112/2016, de 20 de junio; STS 623/2016, de 13 de julio; críticamente Laurenzo Copello, 2019).

No son homogéneas, sin embargo, las consecuencias prácticas que los tribunales extraen de esa caracterización. Para la corriente extensiva, el componente que haría de estas conductas un delito de odio es puramente subjetivo: el móvil discriminatorio que preside el atentado a la dignidad de la víctima, de modo tal que bastaría con demostrar la presencia de ese elemento subjetivo como motivación del acto de humillación o descrédito para dar por completa la tipicidad.

El Tribunal Supremo ha definido los atentados a la dignidad previstos en esta figura de la siguiente forma: descrédito (esto es, disminución o perdida de la reputación de las personas o del valor y estima de las cosas), menosprecio (equivalente a poco aprecio, poca estimación, desprecio o desdén), humillación (herir el amor propio o dignidad de alguien, pasar por una situación en la que la dignidad de la persona sufra algún menoscabo) (STS 656/2007, de 17 de julio).

Por el contrario, la corriente restrictiva se apoya en la caracterización de esta figura como un delito de odio para exigir que el acto objetivamente vejatorio trascienda de algún modo al colectivo discriminado, excluyendo así los atentados a la dignidad puramente aislados o los que tienen lugar en contextos privados sin repercusión pública alguna.

Dos resultados muy diferentes que parecen tener su origen en un mismo concepto: el delito de odio. Es obvio que el problema se encuentra, por tanto, en la propia definición de esta categoría delictiva que con tanta fuerza se viene utilizándose en los últimos tiempos entre nosotros pese a su escasa claridad conceptual. Se hace imprescindible, en consecuencia, una aclaración previa del significado de la categoría de delitos de odio. 


\subsection{Contenido y finalidad de los delitos de odio}

Cuando se plantea el contenido y sentido de los delitos de odio no se puede perder de vista de qué se está hablando y para qué. La clave no está en la formulación gramatical del delito sino en qué se quiere proteger con los delitos de odio o, mejor, qué se puede proteger con una categoría específica de delitos caracterizados por la agravación de la respuesta penal o, en su caso, por la punición específica de ciertas conductas basadas en prejuicios. Por algo se han elaborado finas teorías sobre la configuración y sentido del bien jurídico; por algo existe el principio de exclusiva protección de bienes jurídi$\cos$ (por muy debilitado que se encuentre últimamente).

Quienes afirman que la redacción de nuestra ley penal solo permite una interpretación subjetiva basada en la motivación del autor -versión imperante en la jurisprudencia- en realidad razonan al revés: en lugar de establecer el alcance de la figura penal en función del objeto de protección (función hermenéutica del bien jurídico), parten del texto legal para construir a partir de ahí el objeto de tutela. El bien jurídico deja de jugar su tradicional función limitadora del poder punitivo del Estado para convertirse en un instrumento para justificar una decisión legislativa que se acepta como intocable. Ese es el camino por el que se llega al principio genérico de igualdad que permite identificar el objeto de tutela de los delitos de odio con las características que definen la "identidad personal" de cualquier ciudadano o ciudadana, con independencia de si esas características están o no relacionadas con identidades colectivas históricamente discriminadas (Cancio/Díaz López, 2019, p. 86). Nada que objetar a la coherencia interna de este razonamiento: si se parte de que el fundamento del reproche penal está en la actitud interna del autor (en su odio prejuicioso), lógicamente no hay razón para limitar el alcance de estas figuras solo a quienes odian a personas de determinada raza, etnia o nacionalidad. Si tuviera algún sentido proteger frente al odio, toda la ciudadanía tendría el mismo derecho a que se le protegiera frente a quienes les odian solo por ser quienes son, da igual que se trate de un gitano o de un payo, de un inmigrante subsahariano o de un blanco del barrio de Salamanca, de un marroquí llegado en patera o de un español con varias generaciones de ancestros nacionales.

El problema es qué sentido tiene que nuestra legislación conceda una protección penal específica a las personas solo para preservar su "identidad personal”. Está claro que no se puede tolerar que en nombre del Islam alguien atente contra los feligreses de una iglesia católica o que varias personas 
homosexuales golpeen a una pareja heterosexual que se está besando en una discoteca de ambiente gay. Para eso están los tipos penales de lesiones, amenazas, coacciones, contra la libertad religiosa y tantos otros. La pregunta es si, además, hace falta que a esos católicos se les proteja "por ser católicos", para preservar su identidad como católicos practicantes, o que a la pareja agredida se le proteja "por ser heterosexual". Una cuestión que en realidad nadie contesta por la sencilla razón de que la respuesta es obvia: es evidente que no hay ninguna necesidad de una protección penal reforzada por ser quienes son. En estas circunstancias basta con los tipos penales comunes que protegen la libertad, la vida o la integridad física y moral de cada uno de los ciudadanos y ciudadanas. Porque en un país donde la religión dominante es la católica es obvio que un ataque a su iglesia o a sus feligreses no pone en peligro su identidad como grupo religioso ni crea el riesgo de perder el respeto de la comunidad en la que viven. Como tampoco sucede con las personas que comparten la orientación sexual que constituye la norma en la sociedad en la que vivimos. Por eso precisamente la razón de ser de los delitos de odio hay que buscarla en otro lado: en la historia de opresión de ciertos colectivos históricamente relegados. No hay más que volver la vista a los orígenes de los hate crimes en el país que los inventó para constatar esta realidad.

La historia del desarrollo legislativo de los crímenes de odio en los Estados Unidos de América, pese a sus múltiples particularidades, pone de manifiesto que la finalidad de estos delitos siempre ha estado vinculada con la protección de minorías y colectivos socialmente discriminados. El referente histórico estructural que impulsó la decisión de crear un tipo de delitos basados en prejuicios en aquel país fue su pasado esclavista (Shavers, 2014, pp. 115 y ss.). Con argumentos muy sólidos demuestra Aaronson (2014, p. 190) que las leyes penales de protección de las minorías raciales en USA están íntimamente relacionadas con el papel ideológico que a lo largo de la historia ha desempeñado el Derecho de cara a transmitir la imagen de un Estado capaz de resolver los problemas derivados de la segregación racial. En una línea semejante afirma Lewis $(2013$, p. 36) que el debate legislativo que dio lugar a las primeras leyes federales sobre hate crimes se planteó como un asunto de justicia social hacia las minorías, para hacer patente la responsabilidad colectiva frente a ciertos prejuicios étnicos y raciales profundamente arraigados en la colectividad. Como dice Lawrence (2002, p. 13), la historia de los delitos de odio en los Estados Unidos de América está relacionada con experiencias de exclusión derivadas de hondas fisuras internas en la sociedad. Se constata, pues, que la razón de ser de los delitos de odio está asociada a 
reivindicaciones políticas en favor del reconocimiento pleno de los derechos fundamentales que históricamente la sociedad ha escatimado a amplios sectores de la población marcados por el estigma del color de su piel o su origen étnico o nacional.

Bien es verdad que a partir de los años noventa, con el auge del neoliberalismo, los delitos de odio comenzaron a despolitizarse en USA y en parte perdieron aquella raíz socio-estructural que apuntaba a la responsabilidad colectiva. Las políticas de ley y orden consiguieron desplazar la idea original de injusticia social generadora de prejuicios y discriminación para situar la esencia de los hate crimes en la personalidad perversa del delincuente individual (Lewis, 2013, pp. 41 y ss.), convirtiéndolos así en hechos puntuales atribuidos a sujetos inadaptados y violentos. Una enseñanza histórica que no se debería perder de vista a la hora de trasladar el debate norteamericano a nuestra legislación sobre derecho penal antidiscriminatorio.

Quizás si se tiene en cuenta ese trasfondo ideológico de la política criminal de nuestro tiempo resulte más fácil entender la transformación de los primigenios delitos antidiscriminatorios introducidos en el Código penal de 1995 en unos difusos "delitos de odio" que con este cambio conceptual (que no solo terminológico) consiguen liberarse del incómodo significado político que implica reconocer la existencia de grupos sociales injustamente estigmatizados y desviar la atención a la reprochable actitud intolerante de ciertos individuos violentos que se mueven por prejuicios inaceptables en una sociedad democrática (tal como surge del modelo subjetivista de la motivación). No le falta razón a Fuentes Osorio (2017, p. 4) cuando señala que el uso del término "odio" para definir estos delitos abre el camino para desvalorar “otros ámbitos distintos al discriminatorio". Si el fundamento de los delitos de odio se sitúa en la motivación, en una emoción "intolerable”, la atención se fija en el hecho mismo de actuar por un prejuicio y no en el contenido del prejuicio que está en la base de la conducta. Por eso ya no importa si el ataque se dirige a sectores de la población socialmente discriminados o a grupos poderosos y bien situados en la estructura comunitaria.

Muy ilustrativa en este sentido es la Sentencia del Tribunal Superior de Justicia de Cataluña 142/2020, de 22 de junio, que amparándose en la amplitud de las causas de discriminación recogidas en el art. $510 \mathrm{CP}$, sostiene que si bien en un principio los delitos de odio surgieron para proteger a grupos socialmente débiles, el actual "universo de colectivos-diana" ya no permite hacer esa limitación y concluye que el tipo penal "se extiende a cualquier grupo o individuo aunque pueda ser considerado socialmente mayoritario o no desventajado en 
términos políticos, culturales y económicos siempre que comparta el marcador que lo haga destinatario del ataque incitatorio al odio".

El problema de este punto de vista es que sitúa el fundamento del reproche penal únicamente en la forma de pensar del autor del delito, en el componente subjetivo de actuar por "odio", creando así serias dudas sobre su admisibilidad constitucional al acercarse peligrosamente al denostado derecho penal de autor.

Muy distintas son las conclusiones si el fundamento se establece a partir del riesgo que implica pertenecer a un colectivo socialmente discriminado. Porque una acción violenta dirigida contra estos grupos o contra alguno de sus miembros se basa en prejuicios compartidos por amplios sectores de la población. Quienes sufren esos ataques violentos en realidad son víctimas ya de muy distintas formas de rechazo o menosprecio social que se traducen en estereotipos asentados en la cultura dominante y, por eso, como dice Petrosino (1999, p. 269), no caen en el vacío: son el reflejo de una ideología mayoritariamente compartida. Tiene razón Perry (2003, p. 105) cuando sostiene que los delitos de odio solo adquieren sentido en contextos de dominación/ subordinación porque constituyen un mecanismo para confirmar la posición de superioridad del grupo dominante y al mismo tiempo recordar al otro cual es "su lugar".

Nadie discute que unos ciudadanos pueden sentir animadversión hacia otros por infinidad de razones, incluidas las características que definen la identidad diferencial de cada persona, sea en el sentido que sea: tan distintivo es ser africano como europeo; homosexual o heterosexual; español o ecuatoriano. Pero la valoración social de esas particularidades identitarias no es igual para todos y por eso tampoco lo son los efectos que produce un acto basado en esa condición de la víctima. El problema surge cuando la "diferencia” se estigmatiza y se convierte en una fuente de desvaloración social. Y eso sucede cuando la diferencia se interpreta como un déficit, como una carencia entendida en términos de antinormatividad. Está de sobra demostrado que la identificación de la diferencia como un déficit es una construcción sociocultural dependiente de las relaciones de poder: quienes ocupan posiciones de poder marcan el ámbito de lo normativo, lo correcto, lo válido para toda la sociedad; lo que implica a su vez la jerarquización de los grupos sociales y de las personas en función de su mayor o menor adecuación a esos patrones preestablecidos. Como bien dice Perry (2003, p. 99), "el etiquetamiento de lo diferente como deficiente es un proceso social y político que tiene el efecto 
de crear jerarquías a partir de divisiones tales como la raza, la sexualidad o la clase". Y es esa minusvaloración de partida -esa posición de subordinación en la que la "diferencia" sitúa a determinados colectivos o sectores de la población- la que expone a sus miembros al riesgo de sufrir actos de menosprecio, humillación o vejación solo por ser quienes son. Por eso tiene sentido que el derecho conceda a estos grupos una protección adicional que no le hace falta a quienes forman parte de la mayoría hegemónica (Duff y Marshall, 2018, p. 47). En ese sentido se puede convenir con Landa Gorostiza (2018, p. 58) en la idea de que estamos ante grupos "vulnerables", si por tales entendemos, siguiendo a Chakraborti y Garland (2012, p. 506), "todos aquellos grupos o individuos que están empobrecidos, privados de derechos o que están sujetos a discriminación, intolerancia, subordinación y estigma”.

Conforme a este criterio, no es el impulso emocional de actuar movido por un prejuicio lo que justifica la punición (o mayor punición) de quien selecciona a su víctima por su real o percibida pertenencia a un grupo caracterizado por la raza, el origen nacional o étnico, la religión u otros factores similares (siguiendo la conocida definición de delitos de odio de la Organización para la Seguridad y Cooperación en Europa) sino el contenido mismo del prejuicio, el hecho de que esté asociado a la minusvaloración social de determinadas características identitarias de la víctima. Porque es ese componente objetivo el que expone a los miembros de esos grupos a un riesgo particular de ser objeto de agresiones solo por ser como son y, además, multiplica los efectos negativos del hecho.

Los estudios criminológicos realizados especialmente en los países anglosajones han demostrado que los ataques a miembros de grupos discriminados producen efectos emocionales y psicológicos adicionales para la víctima porque se ve resentida su seguridad, obligándola a adoptar una postura defensiva que va minando su autoestima (Lawrence, 2002, p. 40). Pero, sobre todo, en tanto que la razón de la agresión se encuentra en su propia identidad, en el hecho de ser quien es y como es, resulta afectada la dignidad personal de la víctima. La gran diferencia entre un trato desigual y un trato discriminatorio es que el segundo presupone la negación de la condición de ser humano de primera categoría, es un acto de reafirmación de la diferencia entendida como subordinación o desprecio (Laurenzo Copello, 1996, pp. 235 y ss.). A esto se une el efecto que produce sobre el conjunto del grupo afectado cuando por el contexto en el que se realiza tiene aptitud para transmitir un mensaje de desprecio al colectivo como tal, porque de ese modo se debilitan las expectativas de seguridad de todos sus miembros (Landa, 2018, pp. 123 y ss.). 
Por eso Duff y Marshall sostienen con razón que no es la motivación lo que caracteriza como inaceptable un comportamiento de odio, sino el propio significado de la acción: el mensaje de exclusión y opresión que transmite a todo el colectivo (2018, p. 12).

A todo ello cabe añadir el impacto que el acto discriminatorio -el que se dirige contra grupos socialmente subordinados- tiene sobre el propio modelo de convivencia trazado por la Constitución, en el que expresamente se prohíbe la discriminación por raza, religión, sexo, religión, opinión o cualquier otra condición o circunstancia personal o social (art. $14 \mathrm{CE}$ ). El art. 9.2 de la Constitución impone a los poderes públicos la obligación de "promover las condiciones para que la libertad y la igualdad del individuo y de los grupos en que se integra sean reales y efectivas" y sin duda los delitos de odio, en tanto que conductas basadas en prejuicios hacia sectores socialmente estigmatizados, constituyen un obstáculo que debilita las posibilidades de ejercicio pleno de los derechos fundamentales de sus miembros, al tiempo que favorecen la fractura social (Lim, 2009, p. 119), la división de la comunidad en grupos enfrentados (nosotros y los otros).

Por eso se puede concluir que los llamados delitos de odio en realidad son delitos de discriminación. Si prescindimos del mimetismo con otros ámbitos jurídicos muy ajenos a nuestra realidad normativa e histórica, lo único razonable es reencauzar la interpretación de las figuras delictivas que en el derecho español recogen comportamientos relacionados con prejuicios a través de los criterios propios del derecho antidiscriminatorio. Solo de esta manera es posible encontrar una fundamentación razonable para la intervención penal reforzada ante ciertos hechos realizados "por razón” de las características identitarias de la víctima, sea su ideología, religión o creencias, etnia, raza o nación a la que pertenezca, su sexo, orientación o identidad sexual, razones de género, la enfermedad que padezca o su discapacidad (como dice, entre otros, el art. $510 \mathrm{CP})$.

\section{BASES PARA UN INTERPRETACIÓN RESTRICTIVA DEL DELITO DE ATENTADOS A LA DIGNIDAD POR MOTIVOS DISCRIMINATORIOS}

Lo dicho hasta aquí permite inferir que el ataque a una persona por su pertenencia a un colectivo social estigmatizado posee un añadido de lesividad que no recogen los tipos comunes (sea de lesiones, maltrato de obra u otros semejantes) y por eso el Código penal prevé una agravante genérica de 
discriminación (art. 22.4 ${ }^{\mathrm{a}}$ ). Pero precisamente la existencia de esta agravante hace surgir serias dudas sobre la razón que ha llevado al legislador a crear un delito autónomo -el 510.2 a) - en el que aparentemente se protege lo mismo que capta ya la mencionada circunstancia (ataques a la dignidad basados en prejuicios). Porque todo atentado a una persona en razón de su pertenencia a un colectivo discriminado posee un componente humillante y de descrédito que simbólicamente coloca a la víctima en una posición de inferioridad derivada de sus características de identidad. En consecuencia, se hace necesario buscar criterios que permitan delimitar de forma razonable los distintos preceptos antidiscriminatorios que contiene el actual Código penal (o, si se prefiere, las figuras penales reconducibles al concepto de "delitos de odio") sin caer en la tentación de aceptar de manera irreflexiva la yuxtaposición de unas figuras con otras acudiendo al socorrido recurso del concurso de normas, como propone la Circular 7/2019 de la Fiscalía General del Estado a la que sigue una buena parte de las tribunales.

Ante todo, una interpretación sistemática obliga a no perder de vista que el delito que estamos analizando se encuentra recogido junto al que se considera el más genuino delito de odio: la incitación pública al odio, la hostilidad, la discriminación o la violencia contra grupos vulnerables (art. 510.1 CP). Y es opinión común que el objeto de protección de este delito no son las personas en sentido individual sino los propios colectivos discriminados, ya que la especial lesividad de la conducta se encuentra en su aptitud para poner en peligro las condiciones existenciales del grupo como tal, en palabras de Landa Gorostiza (2000, p. 342).

Y lo cierto es que la descripción de la conducta típica recogida en el art. 510.2 apunta hacia esa misma idea ya que expresamente dice que el atentado a la dignidad debe entrañar humillación, menosprecio o descrédito de alguno de los grupos protegidos, de una parte de ellos o de una persona determinada por razón de su pertenencia al grupo. No se trata entonces de cualquier acto vejatorio aislado que tenga por causa alguna de las circunstancias personales contempladas en la ley (por ejemplo, la orientación sexual o el origen nacional). Hace falta, además, que por el contexto en el que se realiza, el acto exprese objetivamente una minusvaloración del grupo al que pertenece la víctima, profundizando así en el estigma social con todo lo que ello representa de negativo para sus miembros, en particular, por el paulatino debilitamiento de las condiciones para el pleno ejercicio de sus derechos fundamentales. 
O DESCRÉDITO DE COLECTIVOS DISCRIMINADOS

Un sector doctrinal interpreta que estaríamos ante una especie de acto preparatorio del delito del art. 510.1 en la medida en que la transmisión de una imagen negativa del colectivo de algún modo vendría a preparar el terreno para futuras incitaciones a la hostilidad, violencia o discriminación contra el mismo (Landa Gorostiza, 2018, pp. 81 y s.; también de Pablo Serrano y Tapia Ballesteros, 2017, p. 8). Un punto de vista complejo teniendo en cuenta que el art. 510.2 exige la lesión de la dignidad y los actos preparatorios por su propia naturaleza captan conductas de peligro. Sin embargo, si lo entiendo bien, tal contradicción no existe porque esta corriente sitúa al bien jurídico protegido por el art. 510.2 más allá de la dignidad individual de la concreta persona afectada para identificarlo con las condiciones de existencia del colectivo como tal.

Solo apelando a ese componente colectivo es posible encontrar algún sentido al delito de humillación de los miembros de grupos vulnerables que introdujo la reforma de 2015 sin caer en una ampliación totalmente injustificada de la intervención penal o en la innecesaria multiplicación de figuras delictivas que castiguen lo mismo (no hay más que pensar en los delitos de injurias o contra la integridad moral). Así lo ha visto correctamente el sector de nuestros tribunales que a partir de una interpretación teleológica exige que el acto vejatorio trascienda de alguna manera al grupo en su conjunto.

Muy clara en esta línea es la Audiencia Provincial de León cuando excluye la aplicación del art. 510.2

a) en un episodio puntual en el que un hombre golpea a otro llamándolo “maricón”. El tribunal argumenta que la finalidad del precepto no es sancionar casos aislados como este sino "conductas que humillan o menosprecian a un determinado colectivo ante la opinión pública, aunque dicha ofensa se haya dirigido contra una persona determinada, pero como integrante de dicho grupo vulnerable" (SAP León, Sección 3a , 376/2020, de 12 de noviembre).

A partir de estas ideas es posible dejar al margen del art. 510.2 los actos de humillación, menosprecio o descrédito basados en alguna condición personal de la víctima que carezcan de la entidad suficiente para repercutir sobre el colectivo, sea porque se trate de hechos aislados o porque estos se produzcan en un ámbito reducido sin apenas trascendencia pública. Este criterio permite descartar la corriente puramente subjetivista que se ha impuesto en parte de nuestros tribunales que configura el delito solo a partir del móvil racista, xenófobo u homófobo del autor, extendiendo el tipo de forma desmesurada y carente de toda justificación. 
Por el contrario, la interpretación restrictiva que aquí se propone permite limitar de modo significativo el ámbito de aplicación del precepto, circunscribiéndolo a casos muy concretos.

Entre ellos se encontrarían los auténticos supuestos de injurias colectivas o atentados a la dignidad dirigidos al grupo como tal, en la línea que contemplaba el Código penal antes de la reforma de 2015.

Un buen ejemplo es el siguiente caso juzgado por la Audiencia Provincial de Madrid: una persona difundió por youtube un vídeo profundamente ofensivo contra los homosexuales en el que, entre otras cosas, se identificaba sodomía, pedofilia y pederastia afirmando que la homosexualidad y la pederastia vienen del mismo tronco y que se trata de una "degeneración anticristiana y por tanto inhumana". Dice la Sentencia que "la dosis de descrédito y menosprecio que encierran estas palabras [para los homosexuales] es sencillamente brutal, intolerable para un ordenamiento jurídico y una sociedad basada en el respeto a la dignidad y la libertad de las personas" (SAP Madrid, Sección 23, 762/2017, de 29 de diciembre).

Por su parte, cuando el acto vejatorio se dirija solo contra uno o varios miembros concretos del colectivo, será preciso que, en atención a la circunstancias concurrentes, posea aptitud para influir de forma negativa sobre la valoración social del grupo en su conjunto, lo que se producirá solo si tiene suficiente trascendencia pública y reviste una gravedad significativa, como sucedió en el caso de los hinchas de un equipo de fútbol europeo que vejaron públicamente a unas mujeres rumanas que les pedían limosna, burlándose de ellas frente a una multitud de personas (SAP Madrid 344/2020, de 17 de septiembre).

La propuesta de interpretación restrictiva del art. 510.2 que he intentado justificar en estas páginas a partir del concepto y sentido de los delitos antidiscriminatorios (hoy llamados delitos de odio) no implica que lo considere un precepto necesario ni mucho menos oportuno. Quizás este tipo penal consiga cubrir algunas lagunas en la tutela de los colectivos sociales discriminados, pero a la vista de la aplicación que de él está haciendo la jurisprudencia es evidente que tiene muchos más efectos negativos que posibles virtudes (Fuentes Osorio, 2017, p. 41). En la práctica está suponiendo un nuevo avance de la corriente punitivista que se empeña en identificar cualquier acto inmoral o socialmente reprochable con una conducta merecedora de sanción penal. 
O DESCRÉDITO DE COLECTIVOS DISCRIMINADOS

\section{REFERENCIAS BIBLIOGRÁFICAS}

Aaronson, E. (2014). From Slave Abuse to Hate Crime. The Criminalization of Racial Violence in American History. New York. Cambridge Univesity Press.

Cancio Meliá, M. y Díaz López, J. A. (2019). ¿Discurso de odio y/o discurso terrorista? Pamplona. Aranzadi.

Chakraborti, N. y Garland, J. (2012). "Reconceptualizing hate crime victimization through the lens of vulnerability and 'difference". Theoretical Criminology $n^{\circ} 16(4)$, pp. 499-514.

Cuerda Arnau, M. L. (1995). "Observaciones en torno a las nuevas figuras de apología”. Boletín del Ministerio de Justicia, n. ${ }^{\circ} 1757$, pp. 86-116.

Díez Ripollés, J. L. (2013). Política Criminal y Derecho Penal. $2^{a}$ edición. Valencia. Tirant lo Blanch.

De Pablo Serrano, A. L. y Tapia Ballesteros, P. (2017). "Discurso del odio: problemas en la delimitación del bien jurídico y en la nueva configuración del tipo penal". Diario La Ley, n. ${ }^{\circ} 8911$, de 30 de enero.

Duff, R.A. y Marshall, S. E. (2018). “Criminalizing Hate?" Legal Studies Research Paper Series. Research Paper Nr. 15-34. University of Minnesota Law School. Documento en línea http://ssrn.com/abstract=2684202. (última consulta 23/6/2021)

Fuentes Osorio, J. L. (2017). "El odio como delito". Revista Electrónica de Ciencia Penal y Criminología, n. ${ }^{\circ}$ 19-27, pp. 1-52.

Landa Gorostiza, J. M. (2000). La intervención penal frente a la xenofobia. Bilbao. Servicio Editorial de la Universidad del País Vasco.

Landa Gorostiza, J. M. (2018). Los delitos de odio. Valencia. Tirant lo Blanch.

Laurenzo Copello, P. (1996). "La discriminación en el Código Penal de 1995". Estudios Penales y Criminológicos, XIX, pp. 219-288.

Laurenzo Copello, P. 2019). "La manipulación de los delitos de odio", en Portilla Contreras, G. y Velázquez Velázquez, F. (dirs.). Un juez para la democracia. Libro homenaje a Perfecto Andrés Ibáñez. Madrid. Dykinson.

Lawrence, F. M. (2002). Punishing Hate: Bias Crimes under American Law. Cambridge and London. Harvard University Press.

Lewis, C. S. (2013). Tough on Hate? The Culture Politics of Hate Crimes. New Jersey and London. Rutgers University Press.

Lim, Н. А. (2009). "Beyond the immediate victim: understanding hate crimes as message crimes", en Perry, B. (ed.), Hate Crimes, Vol. 2 (The Consequences of Hate Crime), Westport. Praeger, pp. 107-122.

Muñoz Conde, F. (2010). Derecho Penal. Parte Especial. Valencia. Tirant lo Blanch. Perry, B. (2003), “Accounting for Hate Crime: Doing Difference”, en Perry, B. (ed.) Hate and Bias Crime. A Reader. New York and London. Routledge, pp. 97-108. 
Petrosino, C. (1999). "Connecting the Past to the Future: Hate Crime in America”. Journal of Contemporary Criminal Justice, 1999, pp. 22-47.

Portilla Contreras, G. (2016). “La represión penal del discurso del odio”, en Álvarez García, F.J. (dir.). Tratado de Derecho Penal español. Parte Especial. IV. Delitos contra la Constitución. Valencia. Tirant lo Blanch, pp. 379-412.

Shavers, C. M. (2014). Criminal Law Dealing with Hate Crimes; functional Comparative Law Germany vs. USA. Fankfurt am Main. Peter Lang ed.

Turpin-Petrosino, C. (2015). Understanding Hate Crimes. New York. Routledge. 